Ewa JURGA-WosIK

Uniwersytet im. Adama Mickiewicza w Poznaniu

\title{
Strukturalne i jakościowe przemiany w mediach lokalnych
}

Streszczenie: Zwrócenie uwagi na media lokalne jest ważne z powodu ich tematycznej bliskości z odbiorcą. Występują najczęściej w czterech głównych typach formatu: tradycyjna prasa drukowana, radio lokalne, telewizja lokalna i portale internetowe. Przeważają ilościowo $\mathrm{w}$ wielu systemach medialnych państw (np. tradycyjna prasa drukowana: w Polsce 2000-2500 tytułów, Niemczech - 1500; np. lokalna prasa w wydaniu cyfrowym: Portugalia - 170 tytułów) odgrywając przy tym istotną rolę w życiu społeczeństw. Z empirycznych badań Anny Przybylskiej wynika, iż regularny kontakt z mediami lokalnymi wpływa pozytywnie na przywiązanie do miejsca zamieszkania i zaangażowanie społeczne mieszkańców. Celem niniejszego artykułu jest przedstawienie problemów, na jakie napotykają polskie media lokalne i kierunków ich rozwoju. Hipoteza badawcza brzmi - przemiany w polskich mediach lokalnych dotyczą zmian strukturalnych i jakościowych. Zmienia się zatem i warsztat dziennikarza, jak i zawartość prasy lokalnej. Jedną z głównych przyczyn tych zmian jest dynamiczny rozwój technologii. Stąd można zadać pytanie o kierunek tych przekształceń i jakie skutki za sobą pociagają, i wreszcie jaką nową jakość w dziennikarstwie lokalnym wprowadzają.

Slowa kluczowe: media lokalne, prasa lokalna, dziennikarstwo

$\mathbf{Z}$ wrócenie uwagi na media lokalne jest ważne $\mathrm{z}$ powodu ich tematycznej bliskości z odbiorcą (Michalczyk, 2010, s. 15). Występują najczęściej w czterech głównych typach formatu: tradycyjna prasa drukowana, radio lokalne, telewizja lokalna i portale internetowe (Michalczyk, 2016, s. 10). Przeważają ilościowo w wielu systemach medialnych państw (np. tradycyjna prasa drukowana: w Polsce 2000-2500 tytułów, Niemczech - 1500; np. lokalna prasa w wydaniu cyfrowym: Portugalia - 170 tytułów) odgrywając przy tym istotną rolę w życiu społeczeństw (Mikułowski-Pomorski, 2008, s. 79; Michalczyk, 2016, s. 27; Polak, 2010, s. 68; Przybylska, 2010, s. 67-68; Rubaj, 2016, s. 40). Z empirycznych badań Anny Przybylskiej wynika, iż regularny kontakt z mediami lokalnymi wpływa pozytywnie na przywiązanie do miejsca zamieszkania 
i zaangażowanie społeczne mieszkańców (Przybylska, 2010, s. 66). Jednak już w latach siedemdziesiątych Walery Pisarek podkreślał, iż krąg czytelników gazety regionalnej jest szerszy, aniżeli centralnej (Pisarek, 1978, s. 62). Wyjątkowość mediów lokalnych wynika z tego również, iż są gwarantem funkcjonowania demokracji na szczeblu lokalnym, zapobiegają też procesom „uniwersalizacji”, powodujących zanikanie lokalnych i regionalnych wartości i norm społecznych oraz są to też zasoby materialne społeczności lokalnej i regionalnej, skupiające zasoby intelektualne, będące elementem lokalnego systemu społecznego (Michalczyk, 2010, s. 15; Lobka-Pietras, 2003, s. 85-95). Media lokalne na tle innych typów, zwłaszcza mediów ogólnokrajowych, częściej wpisują się w model nagłośnienia polityki, w którym rola obywateli i wyborców kreujących zawartość mediów jest niezwykle ważna (Dobek-Ostrowska, 2011, s. 124). Z drugiej strony, inne badania pokazuja, iż media lokalne utrwalają czytelnicze przyzwyczajenia poprzez, jak wskazuje Maria Wojtak - ,nadawanie wypowiedziom reprezentującym określony gatunek kształtu stałego" (Wojtak, 2008, s. 21).

Celem niniejszego artykułu jest przedstawienie problemów, na jakie napotykają polskie media lokalne i kierunków ich rozwoju. Hipoteza badawcza brzmi - przemiany w polskich mediach lokalnych dotyczą zmian strukturalnych i jakościowych. Zmienia się zatem i warsztat dziennikarza, jak i zawartość prasy lokalnej. Jedną z głównych przyczyn tych zmian jest dynamiczny rozwój technologii. Stąd można zadać pytanie o kierunek tych przekształceń, o skutki jakie za sobą pociagają, i wreszcie jaką nową jakość w dziennikarstwie lokalnym wprowadzają. Jednakże, trzeba zaznaczyć, jak słusznie wskazuje Bogusława Dobek-Ostrowska, iż brak jest kompleksowych studiów nad mediami lokalnymi i zatrudnionymi w nich dziennikarzami (Dobek-Ostrowska, 2011, s. 38). Nie ma obecnie badań statystycznych, które jednoznacznie pokazałyby ile jest mediów lokalnych poszczególnych typów i określiłyby szacunkową liczbę zatrudnionych w redakcjach dziennikarzy. Nie znaczy to jednak, iż badania nad mediami lokalnymi nie są prowadzone - wiele wartościowych prac wyszło spod pióra m.in. Mariana Gieruli (Gierula, 2005, 2006), Marka Jachimowskiego (Jachimowski, 2006), Stanisława Michalczyka (Michalczyk, 2000, 2006, 2010, 2016), Włodzimierza Chorązkiego (Chorązki, 1994, 1999), Ryszarda Kowalczyka (Kowalczyk, 2003, 2008) czy Wiktora Peplińskiego (Pepliński, 2001). Swój wkład w badania nad mediami lokalnymi również wnieśli m.in. Lucyna Szot (Szot, 2013), Ilona Biernacka-Ligęza (Biernacka-Ligięza, 2012), Lidia Pokrzycka (Pokrzycka, 
2009), Patrycja Szostok (Szostok, Rajczyk, 2013) i Ewa Jurga-Wosik (Jurga-Wosik, 2015). Nadmienić należy jednak, iż w Polsce dominują badania nad mediami o zasięgu ogólnokrajowym i zatrudnionymi w nich dziennikarzami, które realizowane są często w ramach projektów międzynarodowych (Dobek-Ostrowska, Barczyszyn, Michel, 2013, s. 11-13; Dobek-Ostrowska, Barczyszyn, 2016; Stępińska, Jurga-Wosik, Adamczewska, Secler, Narożna, 2016, s. 37-51; Stępińska, Ossowski 2011a, s. 33-46; Stępińska, Ossowski 2011b, s. 17-30; Stępińska, Ossowski, 2011c, s. 43-62).

Problem zmian strukturalnych i jakościowych w mediach lokalnych, badacze polscy rozważali najczęściej w kontekście przemian politycznych, prawnych, ekonomicznych i społecznych, jakie towarzyszyły rozwojowi polskich środków społecznego przekazu już od połowy lat dziewięćdziesiątych (Filas, 2010, s. 27-54; Gierula, 2005, s. 104; Kosiorowski, 2010, s. 96; Kowalczyk, 2008a, s. 164). Ewoluowała przy tym definicja mediów lokalnych i jej typologia. Obecnie na drukowaną prasę lokalną należy spojrzeć poprzez kryterium terytorialnego rozprzestrzeniania i kryterium tematycznego zainteresowania (Jurga-Wosik, 2015b, s. 81). Jednakże trzeba pamiętać, jak słusznie zauważył Marian Gierula, iż prasa lokalna, choć często, to nie zawsze ma pokrycie z obecnym podziałem administracyjnym państwa (Gierula, 2005, s. 102), czego wyraźnym przykładem jest prasa lokalna ukazująca się na obszarze byłego województwa leszczyńskiego (obecnie na granicy trzech województw - wielkopolskiego, lubuskiego i dolnośląskiego).

Obecne przemiany w mediach w dużej mierze kojarzone są z tzw. kryzysem w mediach (Hofman, Kępa-Figura, 2012a, 2012b). Sytuację kryzysową na gruncie politologii można postrzegać jako zmiany czy trudności, przejawiające się w zaburzeniu zwykłego funkcjonowania, w konsekwencji prowadzące do pogorszenia lub polepszenia zastanego stanu (Chmaj, Sokół, 2001, s. 169-170). Jednocześnie ważne są zwłaszcza dwa procesy, jak podkreśliła Małgorzata Lisowska-Magdziarz - ,transformacja systemowa i pojawienie się nowych technologii medialnych wraz z doświadczeniem intensywnej obecności mediów w życiu jednostek i w życiu zbiorowym" (Lisowska-Magdziarz, 2008, s. 14). Procesy te oczywiście wzajemnie się przenikają i warunkują. Ich konsekwencją, jak wskazuje dalej badaczka (Lisowska-Magdziarz, 2008, s. 14), stała się zmiana typu kultury (jako infrastruktura medialna powiązana ze sposobami jej używania do komunikacji i wymiany idei), a w dalszej kolejności - zmiana stylu (jako przewartościowanie i zmiana hierarchii aksjologicznych). 
Stąd biorąc pod uwagę zawartość treści, media swobodnie od lat 90-tych uczestniczą niemalże we wszystkich aspektach codziennego życia, co więcej - wprowadzają nową jakość w percepcji odbiorców. Ponadto ludzie sami, kierując się własnymi doświadczeniami z mediami, wybierają typ prasy, radia czy telewizji najbardziej im bliski mentalnie. Korzystaja $\mathrm{z}$ niego $\mathrm{w}$ wybranym czasie, miejscu i sytuacji, a pozwalają na to nowe technologie (przykładem mogą być tytuły lokalne dostępne w Internecie, których odbiór następuje poprzez telefon komórkowy). Interesujące stanowisko w sprawie przemian, jakie objęły polskie media po 1989 roku przedstawił Ryszard Filas, typując je w osiem faz (R. Filas, 2010, s. 30), w które to wpisują się media lokalne, zwłaszcza w fazę pierwszą i drugą (powstaje: prasa prywatna - np. „Gazeta Wschowska”, tytuły samorządowe - np. „Przegląd Górowski”, organizacji politycznych - np. „Solidarność Leszczyńska” oraz przekształceniom ulega status prawny tygodników KW PZPR - np. „Panoramy Leszczyńskiej”), fazę siódmą (np. powstanie portalu „Radio Elka”) i fazę ósmą (np. w Lesznie - m.in. dziennik „ABC”, tygodniki - „Panorama Leszczyńska” z własnym portalem i „Reporter Leszczyński” oraz „Radio Elka” i jego portale wraz z tygodnikiem „Dodatek”) ${ }^{1}$.

Obecnie, trudno jest jednoznacznie stwierdzić, bez pogłębionych badań, iż media lokalne dotknął tzw. kryzys ekonomiczny. Jednakże problemy finansowe występują, a są związane z malejącą sprzedażą nakładu i rzadszym dostępem ogłoszeniodawców, także konkurencyjnością czasopism bezpłatnych i płatnych sieciowych. Media lokalne borykają się nieustannie z problemem kolportażu, szczególnie w gminach wiejskich. Niedogodnością może być również działalność wielu mediów lokalnych (prasy, radia, telewizji) dotowanych przez samorząd terytorialny, co sprawia, że pozostałe media tracą na tej nierównowadze. Aspekt ten dotyczyć może nie tylko prasy typu samorządowego, ale też prywatnego (może to

${ }^{1}$ Faza I nacechowana była żywiolowym entuzjazmem nowych wydawców $i$ nadawców oraz wymuszonymi przeksztatceniami starych tytutów (od maja 1989 r. do połowy 1991 r.), faza II dotyczyła pozornej stabilizacji i zmian podskórnych w prasie i radiu (od połowy 1991 r. do końca 1992 r.) oraz faza VII była wstępna przebudowq oferty mediów tradycyjnych wobec spodziewanej inwazji nowych technologii medialnych w latach 2004-2007 i faza VIII trwająca od 2008 roku do dzisiaj jako realna konfrontacja mediów tradycyjnych z nowymi technologiami medialnymi w warunkach spowolnienia gospodarczego (w postaci-zahamowania tempa wzrostu PKB, wzrostu inflacji $i$ wzrostu bezrobocia). Rok 2008 to również początek międzynarodowego kryzysu ekonomicznego, którego pierwszym przejawem stało się bankructwo we wrześniu tego roku wielu znanych banków amerykańskich. 
być zlecenie ze strony władz lokalnych na redagowanie stron w prasie wydawców prywatnych - np. dziennik „ABC”). Subwencjonowane przez władze publiczne media zakłócają konkurencję na lokalnym rynku mediów (zwłaszcza odnośnie działalności reklamowo-ogłoszeniowej) i nie spełniają standardów dziennikarskich (np. w dziedzinie kontroli i krytyki społecznej). Na podobne problemy napotykają prywatni lokalni nadawcy radiowo-telewizyjni. Rynek lokalnych mediów elektronicznych nieustannie ewoluuje (likwidacja lokalnych nadawców poprzez ich łączenie, konsolidację oraz wchłanianie przez sieci ogólnokrajowe i regionalne o różnym kapitale), co jest wyjaśniane niskimi wpływami z nieukształtowanego rynku reklamy lokalnej oraz rosnącymi kosztami inwestycyjnymi (Kosiorowski, 2010, s. 105). Zjawiska te są wynikiem powiązań własnościowych, programowych i reklamowych niezależnych dotąd podmiotów. W 2002 roku 151 lokalnych stacji radiowych było w rękach 129 właścicieli osiem lat później istniało nieco ponad 40 nadawców lokalnych funkcjonujących na małych rynkach lokalnych, w miastach poniżej 100 tysięcy mieszkańców i mniejszych (GUS, Kosiorowski, 2010, s. 106). Problemy natury ekonomicznej i prawnej pojawiają się przed wydawcami i dziennikarzami, przede wszystkim w związku z funkcjonowaniem i wykorzystaniem mediów w Internecie (Hayn, 2012, s. 115-116). Wymienić można np. problematykę rejestracji serwisów i portali internetowych oraz odpowiedzialność prawną ich właścicieli, w tym odpowiedzialność za wpisy Internautów.

W rezultacie media lokalne nie tyle co przeszły drogę od pluralizmu do komercjalizacji, co raczej od monopolu do koncentracji. Problem konkurencyjności bezpłatnych gazet i sieciowania tytułów lokalnych, jest szczególnie widoczny w Wielkopolsce (np. 14 tytułów lokalnych jest częścią „Głosu Wielkopolskiego”), z wyjątkiem prasy lokalnej leszczyńskiego regionu wydawniczego, posiadającego bogate tradycje czasopiśmiennicze. Ostatnie lata pokazały również, iż te nie cieszą się zbytnim zainteresowaniem odbiorców (choć to nie przesądza o ich istnieniu), czego wymiernym efektem jest spadek jednorazowego nakładu i zmniejszenie liczby stron periodyków, a niejednokrotnie też zmiana częstotliwości ukazywania się pisma. Jednocześnie media lokalne od początku swojego istnienia borykały się z problemami ekonomicznymi, technologicznymi i warsztatowymi. W celu ratowania swojej pozycji, w ostatnim dziesięcioleciu media lokalne włączyły się w nurt konwergencji mediów (np. „Gazeta Kościańska” i jej portal; „Panorama Leszczyńska" i jej portal). 
Wydawców prasy lokalnej można podzielić, jak wskazuje Ryszard Kowalczyk łącznie na 14 charakterystycznych grup rodzajowych (Kowalczyk, 2010, s. 92). Jednakże w Polsce ogólnoinformacyjne media lokalne ukazują się głównie z inicjatywy samorządów terytorialnych i wydawnictw prywatnych (komercyjnych). Dominują tygodniki wśród prasy wydawców prywatnych, a wśród wydawców samorządowych - miesięczniki i dwumiesięczniki. Obecnie w Polsce dominują miesięczniki (44,5\%), na drugim miejscu plasują się tygodniki $(22,8 \%)$, a następnie - dwumiesięczniki i czasopisma z rzadszym periodem (22,5\%), a tylko nieliczne to dzienniki - 0,4\% (Izba Wydawców Prasy, 2014). To samo źródło wskazuje, iż nakład większości tytułów (ponad 77\%) nie przekracza 2 tysięcy egzemplarzy. Nakład powyżej 10 tysięcy egzemplarzy osiąga tylko ok. 2 proc. tytułów, a nieliczne $\mathrm{z}$ nich osiagają ponad 25 tys. nakładu i są to zazwyczaj płatne tygodniki o bogatej tradycji wydawniczej - np. „Tygodnik Zamojski”, „Tygodnik Siedlecki”, „Tygodnik Podhalański” i „Panorama Leszczyńska”. Obecnie najlepiej sprzedające się tygodniki lokalne nie są wydawane przez duże koncerny, tylko przez lokalne przedsiębiorstwa, co więcej nie mają też dużych nakładów. Wśród poddanych analizie tytułów w 2016 r. tylko w dwóch przypadkach sprzedaż przekraczała 15 tysięcy egzemplarzy - wspomniane już - „Tygodnik Zamojski” (22 498 jednorazowego nakładu) i ,Tygodnik Siedlecki” (18 068 jednorazowego nakładu), a tuż za nimi uplasował się „Tygodnik Podhalański” (14 012 jednorazowego nakładu) (Kalińska, 2016).

Prasa lokalna należy zatem do pism niskonakładowych, podobnie na zróżnicowanym typologicznie leszczyńskim rynku wydawniczym - nakład w szczegółowej analizie pokazuje olbrzymią dysproporcję między prywatnymi tygodnikami (5000-25 000 egz. jednorazowego nakładu) a samorządowymi miesięcznikami, dwumiesięcznikami i kwartalnikami (oscyluje od 450 do 1000 egz. jednorazowego nakładu). Znaczna ilość czasopism lokalnych ukazuje się w formacie A4. Prasa bezpłatna występuje zarówno wśród wydawnictw prywatnych, jak i samorządowych, przy czym trend ten widoczny jest w mediach lokalnych na przestrzeni ostatnich dziesięciu lat. Z kolei prasa płatna jest sprzedawana detalicznie częściej w placówkach handlowych niż za pośrednictwem sieci kolportażowych czy w prenumeracie. Ta ostatnia jest elementem stabilizacji rynkowej pozycji gazety (nawet gdy generowany zysk jest mniejszy poprzez niższą cenę $\mathrm{w}$ prenumeracie) i sprzyja rozwijaniu planów długoterminowych. Korzyści z prenumeraty związane są z zapłatą z góry za kolejne wydania (Kowalski, Jung, 2006, s. 126). Stąd też zachęca do 
niej prasa lokalna (prenumerata w formie czasopisma drukowanego bądź wydania elektronicznego). Prasa lokalna coraz częściej koncentruje się wokół drukarni Polskapresse i Agora. Coraz więcej tytułów ukazuje się w wersjach pełnych i ograniczonych w formie elektronicznej. Tradycyjne drukowane media lokalne dominują w regionach wydawniczych. Obok nich dostępne są lokalne radia (niezależne bądź sformatowane) o zasięgu mikroregionalnym i lokalne telewizje internetowe, a także kablowe. W praktyce wydawnictwa lokalne posiadają zazwyczaj strukturę liniową płaską, która charakteryzuje się małą ilością szczebli hierarchicznego zarządzania (Kaczmarczyk, 2009, s. 149). Zaletą jest więc zbliżenie kierownictwa do bezpośrednich wykonawców i tym samym skrócenie drogi przesyłania poleceń oraz przeprowadzania kontroli. W typowej redakcji lokalnej występuje brak specyfikacji zawodowej, a zatem dziennikarze zajmują się wszystkimi elementami procesu redakcyjno-wydawniczego (od redagowania poprzez składanie gazety po kolportaż). W tej materii jednak zdarzają się wyjątki (Jurga-Wosik, 2010, s. 232). Wymienić tutaj należy gazety wydawców prywatnych o stosunkowo dużym nakładzie i zasięgu kolportażu. W tej prasie najczęściej wyróżnia się cztery działy spełniające wyspecjalizowane funkcje i zadania: redakcyjny (wydawniczy), techniczny (produkcyjny), reklamowy (w tym promocji i marketingu) i kolportażowy (dystrybucji i sprzedaży). Poza redaktorem naczelnym istotną funkcję w prasie lokalnej, pełni redaktor techniczny - odpowiedzialny za skład, łamanie i druk pisma. Pozostali członkowie redakcji odpowiadają za przydzielone im zadania. Rzadko natomiast $w$ redakcjach powoływano zastępcę redaktora. Podobna sytuacja dotyczy sekretarza redakcji, który odpowiada za organizację redakcji, a szczególnie za terminowe zebranie i przygotowanie materiałów prasowych lub wykonanie korekty do kolejnej edycji pisma. Warto również nadmienić, iż podążając za innowacjami w sferze technologii, struktura zmieniła się po $2004 \mathrm{r}$. (wtedy też zaczęto tworzyć gazety lokalne w Internecie). Dziennikarze lokalni wywodzą się z różnych środowisk zawodowych. W prasie samorządowej będą to w większości pracownicy instytucji samorządowych, ośrodków kulturalnych czy bibliotek. Natomiast w prasie prywatnej przeważają dziennikarze, parający się piórem już w latach osiemdziesiątych, a niekiedy i siedemdziesiątych. Należy jednak podkreślić zróżnicowane przygotowanie do zawodu dziennikarza. Generalnie mimo braku profesjonalnego przygotowania do tworzenia czasopism lokalnych (z wyjątkami), to zazwyczaj dziennikarze lokalni dysponują dobrymi źródłami informacji i cechuje ich spora determinacja (Michalczyk, 2016, s. 29). 
W pierwszej połowie lat dziewięćdziesiątych to wystarczyło do budowania lokalnego wydawnictwa. Na dalszy plan odsunięto sprawy finansowe i nierzadko rejestrację czasopisma, co dzisiaj wydaje się rzadkie. Obecnie wiarygodność pisma jest niezwykle ważnym elementem w pozyskiwaniu czytelników i reklamodawców. W związku z tym redakcje zabiegają o wyróżnienie ich jako przedsiębiorstwa medialnego.

Niewattpliwie tradycyjne drukowane media lokalne mogą być wypierane lub są wspierane przez ich odpowiedniki elektroniczne, co więcej - jak wskazuje Stanisław Michalczyk - można już mówić o zjawisku tzw. „hiperlokalności”, czyli „geograficznej mikropłaszczyzny komunikacyjnej" (Michalczyk, 2016, s. 29). Stąd wydawcy w odpowiedzi na rosnącą konkurencję coraz częściej sięgają po nowe rozwiązania technologiczne. Wydania elektroniczne współistnieją z tradycyjnymi mediami, a także - strony w Internecie, blogi i portale są tego przejawem. Z jednej strony e-wydania prasy lokalnej wspierają tradycyjne wydania tytułów. Z drugiej - stanowią też środek promocji oraz źródło informacji o redakcji, wydawcy i działalności reklamowej. Redakcje prasy lokalnej w porozumieniu z firmami informatycznymi częściej zakładają własne strony internetowe o nieskomplikowanej prezentacji pisma (np. „Gazeta Rawicka"), aniżeli korzystają z innych rozbudowanych platform internetowych. W większości postacie - wydania są wyłącznie elektroniczną kopią wersji drukowanej, gdyż układ i zawartość serwisu w całości nawiązują do wersji tradycyjnej (np. „Wiadomości Jutrosińskie”). W rezultacie wydawcy traktują e-wydanie jako alternatywny dostęp do swoich czytelników (Kowalski, Jung, 2006, s. 131). Za przygotowanie e-gazety odpowiadają najczęściej samodzielne zespoły redakcyjne, jednakże są to nadal te same osoby, które uczestniczą w procesie powstania prasy drukowanej. Wydawcy spodziewali się, że poprzez związek tradycyjnych mediów z Internetem i ich konwergencją, zwiększy się liczba czytelników (np. darmowy dostęp do e-archiwum w wyniku zakupu prenumeraty prasy drukowanej). Koszty dystrybucji online są niższe niż w przypadku dystrybucji tradycyjnej, choć oczywiście wymagają określonego nakładu kapitału na zasoby komputerowe, serwery i dzierżawę łączy telekomunikacyjnych. Ważne jest również to, iż e-gazeta pozwala dokonywać na bieżąco oceny stopnia zainteresowania odbiorców poszczególnymi tematami i autorami (sondowanie opinii, możliwość zamieszczania komentarzy przez czytelników). Przy czym, dziennikarz częściej pracuje w domu, co zaburza dotychczasowy wypracowany przez lata warsztat dziennikarza, opierający się m.in. o dyskusję w redakcji nad zebranym materiałem, a w rezultacie ma wpływ na formę 
i zawartość publikacji (Michalczyk, 2016, s. 11; Kopecka-Piech, 2011, s. 19). Wydania mediów w Internecie nie tylko lokalnych, ale zawierających lokalne treści zaspakajają w wielu przypadkach potrzebę informacji o najbliższym otoczeniu (Michalczyk, 2016, s. 31).

Niepowodzenia prywatnych mediów lokalnych są niejednokrotnie usprawiedliwiane przez badaczy i środowisko dziennikarzy. Dyskusja dotyczy występowania na rynku mediów, obok inicjatyw prywatnych, czasopism wydawanych przez samorząd terytorialny. W istocie tym drugim zarzuca się: po pierwsze - pozycja ekonomiczna prasy samorządowej jako uprzywilejowanej jest lepsza, ponieważ jest utrzymywana z subwencji instytucji samorządowej, po drugie - prasa samorządowa - nie realizuje roli czwartej władzy jako kontrolera życia publicznego, gdyż działa zgodnie z założeniami władzy lokalnej i po trzecie - dziennikarze są pracownikami instytucji samorządowej - redakcja więc nie ponosi kosztów utrzymania dziennikarza (Adamczyk, 2011, s. 179-195; Bodnar, Bychawska-Siniarska, 2010). Zaburzona jest funkcja kontrolna pisma, szczególnie w tych gminach, gdzie nie ma konkurencji. Innym problemem jest wypieranie lub zastępowanie mediów lokalnych w dużych aglomeracjach miejskich prasą ogólnopolską, rzadziej regionalna, gdyż ta w dużej mierze została już przejęta przez koncerny zagraniczne i jest tylko dodatkiem do prasy krajowej. Wreszcie trzeba też wspomnieć o koncentracji mediów lokalnych nie tylko w wymiarze przejmowania wydawnictw, ale też w większości przypadkach korzystania z usług drukarni. Powszechnie wiadomo, że duże koncerny mają w tym zakresie większe możliwości, aniżeli małe wydawnictwa. Koncerny prasowe takie jak Agora czy Polskapresse (część koncernu Verlagsgruppe Passau) na drodze swojego rozwoju utworzyły sieci własnych drukarni. Z jednej strony, gwarantują one wydawcom zmniejszenie kosztów druku swoich tytułów, a z drugiej strony, zwiększenie przychodów o wpływy z druku tytułów należących do innych wydawnictw, tak jak to jest w przypadku prasy lokalnej (np. „Kuriera Lokalnego”). Swoistą formą współpracy są też porozumienia niezależnych wzajemnie mediów lokalnych (Majewski, 2005, s. 52-54) co do zamieszczania wspólnych reklam, druku w jednej drukarni czy kolportowaniu wspólnego dodatku telewizyjnego czy branżowego np. dotyczącego rolnictwa (m.in. „Panorama Leszczyńska” i „Gazeta Kościańska” partycypują we wspólnym dodatku telewizyjnym - Tele Wizja). Poszczególne wydawnictwa również dołączają do swoich macierzystych tytułów dodatki branżowe (np. Południowa Oficyna Wydawnicza wydaje miesięcznik „Wieści Rolnicze”). W związku z tym, 
druga dekada funkcjonowania mediów lokalnych przyniosła wiele zmian, a w szerszym kontekście, także w kategorii - ekonomiki mediów.

Od pierwszej dekady istnienia pism lokalnych źródłami finansowania przedsięwzięć prasowych pozostają - sprzedaż egzemplarzowa w przypadku prasy płatnej oraz wpływy z reklam i ogłoszeń. W ostatnich latach - z uwagi na znikomą ilość reklamodawców i ogłoszeniodawców w prasie samorządowej, jedynym rozwiązaniem istnienia tego typu pism na rynku stało się w pełni jego dotowanie, czego przejawem jest bezpłatny obieg (np. „Przegląd Górowski”). Z drugiej strony istnieje też bezpłatna prywatna prasa lokalna (np. „Kurier Gostynia”).

Obserwując współczesne realia funkcjonowania mediów lokalnych, można sądzić, iż tzw. kryzys ekonomiczny był pretekstem do zmiany polityki organizacji i zarządzania tytułami. Zaostrzył on kwestie związane z ograniczeniem niezależności mediów lokalnych, mając na uwadze partykularne intencje nadawcy. Badacz mediów regionalnych i lokalnych Adam Szynol (Szynol, 2007, 113) wyróżnił 10 czynników ograniczających pracę dziennikarzy z podziałem na uwarunkowania wewnętrzne i zewnętrzne (zob. tab. 1). Do czynników ograniczających zaliczył - kompetencje, ekonomię, system motywacyjny, powiązania właściciela lub zarządzających medium z biznesem, zależności polityczne, organizacja pracy $\mathrm{w}$ redakcji, zasięg medium i target, warunki techniczne i sprzęt, konkurencja oraz inne. Problematyka ta była wcześniej podnoszona w literaturze przedmiotu m.in. przez Marka Jachimowskiego (Jachimowski, 2006, s. 31-39) i Mariana Gierulę (Gierula, 2006, s. 82-92). $\mathrm{W}$ istocie zwrócono uwagę na problemy związane z następującymi kwestiami - czasopisma wydawców prywatnych są przedsiębiorstwami na rynku oraz prasa lokalna jest związana relacjami z wszelkiego typu grupami nacisku funkcjonującymi w danej społeczności lokalnej w różnych strefach, czego konsekwencją są utrudnienia w wewnętrznej działalności pisma (Gierula, s. 88-90).

Tabela 1

\section{Czynniki ograniczające pracę dziennikarzy z podziałem na uwarunkowania wewnętrzne i zewnętrzne}

\begin{tabular}{||c|l|l||}
\hline $\begin{array}{c}\text { Czynnik } \\
\text { ograniczający }\end{array}$ & Uwarunkowania wewnętrzne & Uwarunkowania zewnętrzne \\
\hline 1 & \multicolumn{1}{|c||}{2} & \multicolumn{1}{|c}{3} \\
\hline Kompetencje & $\begin{array}{l}\text { - brak odpowiedniego wykształ- } \\
\text { cenia, } \\
-\begin{array}{l}\text { wchodzenie do zawodu bez sta- } \\
\text { żu, bez tzw. terminowania, } \\
\text { zbyt młody wiek }\end{array}\end{array}$ & $\begin{array}{l}\text { wysoka uznaniowośc w kestii } \\
\text { zatrudnieni osób na kierowniczych } \\
\text { stanowiskach bez odpowiednich } \\
\text { kwalifikacji }\end{array}$ \\
\hline
\end{tabular}




\begin{tabular}{|c|c|c|}
\hline 1 & 2 & 3 \\
\hline Ekonomia & $\begin{array}{l}\text { - studia, } \\
\text { - życie rodzinne, } \\
\text { - inne zajęcia niepozwalające na } \\
\text { poświęcenie liczby godzin na } \\
\text { pracę zawodową }\end{array}$ & $\begin{array}{l}\text { - brak stałych pensji lub } \\
\text { - minimalne wynagrodzenie, } \\
\text { - ,wierszówka” wymuszająca } \\
\text { pracę na akord, } \\
\text { - przymuszanie do samozatrud- } \\
\text { niania }\end{array}$ \\
\hline $\begin{array}{l}\text { System moty- } \\
\text { wacyjny }\end{array}$ & $\begin{array}{l}\text { - niejasne zasady przyznawania } \\
\text { dodatków lub } \\
\text { - ich niewłaściwe stosowanie } \\
\text { wpływają demotywująco }\end{array}$ & $\begin{array}{l}\text { - brak jasnych kryteriów lub } \\
\text { - ich wybitna uznaniowość, } \\
\text { - często kryteria oparte na konek- } \\
\text { sjach towarzyskich }\end{array}$ \\
\hline $\begin{array}{l}\text { Powiązania } \\
\text { właściciela lub } \\
\text { zarządzających } \\
\text { medium }\end{array}$ & $\begin{aligned} \text { - } & \text { dziennikarz musi się podporząd- } \\
& \text { kować albo } \\
\text { - } & \text { zmienić miejsce pracy albo } \\
& \text { ostatecznie zmienić profesję }\end{aligned}$ & $\begin{array}{ll}\text { - instrumentalne } & \text { traktowanie } \\
\text { dziennikarzy, } & \\
\text { - prymat działów handlowych } \\
\text { nad newsroomem }\end{array}$ \\
\hline $\begin{array}{l}\text { Zależności } \\
\text { polityczne }\end{array}$ & $\begin{array}{l}\text { jeśli sympatie polityczne są zgod- } \\
\text { ne ze strategią redakcji, weryfika- } \\
\text { torem stopnia wiarygodności me- } \\
\text { dium są odbiorcy }\end{array}$ & $\begin{array}{l}\text { - } \text { redakcja, licząc się } \mathrm{z} \text { interesami } \\
\text { przełożonego, unika tematów } \\
\text { kontrowersyjnych, } \\
\text { - autocenzura }\end{array}$ \\
\hline $\begin{array}{l}\text { Organizacja } \\
\text { pracy } \\
\text { w redakcji }\end{array}$ & $\begin{array}{l}\text { - nieumiejętność zorganizowania } \\
\text { własnego stanowiska pracy, } \\
\text { - brak otwartości i kontaktowości } \\
\text { w stosunku do współpracowni- } \\
\text { ków }\end{array}$ & $\begin{array}{l}\text { - zatrudnianie osób nieumieją- } \\
\text { cych zarządzać zespołem dzien- } \\
\text { nikarskim, } \\
\text { - } \text { brak kompetencji, } \\
\text { - } \text { konflikty wśród kadry zarządza- } \\
\text { jącej przenoszą się na stosunki } \\
\text { wewnątrz redakcji }\end{array}$ \\
\hline $\begin{array}{l}\text { Zasięg } \\
\text { medium, } \\
\text { target }\end{array}$ & $\begin{array}{l}\text { - mała możliwość rozwoju i awan- } \\
\text { su w medium lokalnym lub } \\
\text { - w medium o zawężonej tema- } \\
\text { tyce }\end{array}$ & $\begin{aligned} \text { - } & \text { brak precyzyjnego określenia } \\
& \text { odbiorcy, } \\
\text { - } & \text { niewłaściwe pozycjonowanie } \\
& \text { tytułu lub } \\
\text { - } & \text { niewłaściwe rozmieszczenie treści }\end{aligned}$ \\
\hline $\begin{array}{l}\text { Warunki tech- } \\
\text { niczne, sprzęt }\end{array}$ & $\begin{array}{l}\text { - niechęć i brak nawyku samo- } \\
\text { kształcenia, } \\
\text { - nieznajomość nowych techno- } \\
\text { logii }\end{array}$ & 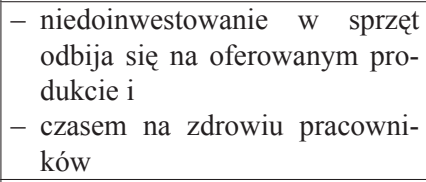 \\
\hline Konkurencja & $\begin{array}{l}\text { - konieczność walki o bycie } \\
\text { pierwszym, } \\
\text { - konieczność walki o dostęp do } \\
\text { źródeł informacji }\end{array}$ & $\begin{aligned} \text { - } & \text { pogoń za newsem za wszelką } \\
& \text { cenę, } \\
\text { - } & \text { niskie pensje, bo budżety rekla- } \\
& \text { mowe dzielą się na więcej firm }\end{aligned}$ \\
\hline Inne & $\begin{array}{r}\text { - brak czasu na dokształcanie, } \\
\text { - nienormowany czas pracy, czę- } \\
\text { sto oznacza jego nielimitowanie }\end{array}$ & $\begin{array}{l}\text { w przypadku mediów z oddziałami } \\
\text { lokalnymi - zbyt duże uzależnienie } \\
\text { od centrali, za wczesny deadline } \\
\text { i ograniczenie objętości wydania }\end{array}$ \\
\hline
\end{tabular}

Źródło: A. Szynol (2007), Dziennikarz lokalny w obliczu interesów politycznych i biznesowych redakcji, w: Media w Polsce. Pierwsza władza IV RP?, red. M. Sokołowskiego, Warszawa, s. 113. 
Nowych rozwiązań niwelujących stagnację na rynku elektronicznych mediów lokalnych, poszukują nadawcy radiowi i telewizyjni wykorzystując konwergencję mediów (np. w postaci - tworzenia nowych portali w sferze radia internetowego, ogłoszeń i hobby). Zbigniew Kosiorowski podkreśla, iż przyczyny regresu elektronicznych mediów lokalnych upatrywać należy w częstym zjawisku likwidacji poszczególnych lokalnych nadawców poprzez ich łączenie się, konsolidację oraz wchłanianie przez sieci ogólnokrajowe i regionalne o różnym kapitale, zarówno polskim, jak i zagranicznym (Kosiorowski, 2010, s. 95). Problem też dotyczy utrzymania przekazu lokalnego (stosunek informacji z obszaru nadawania do ilości prezentowania materiału muzycznego czy wiadomości z kraju i zagranicy) przez nadawców lokalnych. Badacze niejednokrotnie powtarzają, iż w państwach UE, w przeciwieństwie do Polski, można znaleźć szczególne przykłady dbałości o ustalenie norm, obowiązków i zasad funkcjonowania lokalnych mediów elektronicznych oraz celów, a także metod realizacji polityki państwa w zakresie radiofonii i telewizji lokalnej (np. w Wielkiej Brytanii, Francji, Niemczech, Włoszech, Słowenii, Łotwie i Serbii). Dbałość o elektroniczne media lokalne zasadza się w następujących obszarach tematycznych - kryterium lokalności, obowiązków organów regulacyjnych, regulacja sieci, sposoby finansowania nadawców lokalnych oraz gwarantowanie pluralizmu poprzez zapobieganie koncentracji (Murawska-Najmiec, 2005, s. 2). Na tle krajów europejskich w Polsce brakuje przede wszystkim działań kompensujących reprezentację nadawców lokalnych w postaci dofinansowania lokalnych stacji radiowych i telewizyjnych (np. w Niemczech i we Włoszech nadawcy lokalni mogą ubiegać się o zwrot poniesionych kosztów bądź o ulgi podatkowe, jeżeli przeznaczają minimum $70 \%$ dziennego czasu nadawania na tematykę społecznie użyteczną, ważną dla lokalnego odbiorcy). O ile w wielu państwach UE zagwarantowano ochronę mediów lokalnych (kodyfikacje, normy, systemy preferencji, nadzór nad zadaniami powierzonymi tym mediom) to w Polsce sytuację ekonomiczną elektronicznych mediów reguluje rynek. I tak, jak podaje Zbigniew Kosiorowski - z około 150 stacji, które otrzymały koncesję $\mathrm{w}$ dwóch postępowaniach $\mathrm{z}$ lat 1994-1997, obecnie przetrwało nieco ponad czterdzieści (Kosiorowski, 2010, s. 100).

Obserwacja działalności współczesnych mediów lokalnych skłania do przemyśleń, iż media te od początku swojego funkcjonowania, czyli od lat 90. ulegają przekształceniom jakościowym i strukturalnym, przy czym ten pierwszy element silniej się rozwijał (zmienia się zawartość 
prasy: sposób relacjonowania i szata graficzna - efekt profesjonalizacji dziennikarstwa), aniżeli drugi (dominują kilkuosobowe redakcje). Należy zgodzić się z nadal aktualnym poglądem Sylwestra Dzikiego i Włodzimierza Chorązkiego, iż media lokalne przeszły trzy etapy rozwoju: heroiczno-społecznikowski, polityczny i rynkowy, a ich przyszłość zależeć będzie od takich elementów, jak - zasobności wydawcy i możliwości finansowania deficytu prasy, profesjonalizmu zespołu redakcyjnego oraz marketingowego, wielkości i rodzaju rynku odbiorców i reklamodawców oraz sprawności kolportażu (Dziki, 2000, s. 138).

W obliczu braku badań całościowych nad mediami lokalnymi trudno jest wskazać moment załamania się rynku wydawniczego mediów lokalnych. W tym wymiarze, mamy do czynienia $\mathrm{z}$ wieloma regionami wydawniczymi i osłabienie regionu wydawniczego należy badać jako indywidualny przypadek, biorąc pod uwagę m.in. sytuację ekonomiczną regionu, tradycje wydawnicze danego obszaru czy współczesne zaangażowanie odbiorców. Jednocześnie, należy stwierdzić, że obserwowane zmiany jakościowe i strukturalne w mediach lokalnych wskazują na erozję tychże mediów. Trudno nie zauważyć, iż każdego roku spora część czasopism zmienia szatę i układ graficzny czasopism, zmniejsza ilość stron i decyduje się na wersję on-line, nie zatrudniając w większości redakcjach - nowych dziennikarzy (od dekady w stopkach redakcyjnych są raczej te same osoby). W rezultacie niektóre redakcje rezygnują z wersji drukowanej, by po kilku latach, w wyniku małego zainteresowania odbiorcy i niewielkiego zainteresowania reklamodawcy zlikwidować pismo (np. „Słowo Ziemi Wschowskiej”, „Gazeta Gostyńska”). Innym rozwiązaniem jest włączenie czasopisma do spółki medialnej („Dzień Wolsztyński”).

Badania ankietowe przeprowadzone w 2010 roku przez PBC pokazały, że wszystkie media mają swoje miejsce na rynku i pozycja żadnego z nich nie jest wyraźnie zagrożona (Polskie Badania Czytelnictwa, 2010). Podobnie zauważono już wcześniej, chociażby w systemie medialnym Wielkiej Brytanii (Adamowski, 2007, s. 190). Interesujące są zwłaszcza cechy wymagane od poszczególnych mediów. Jak wskazał Stanisław Michalczyk - „logika dziennikarstwa lokalnego nastawiona jest na relacjonowanie, a nie objaśnianie rzeczywistości” (Michalczyk, 2016, s. 14). Zatem drukowana prasa lokalna powinna m.in. być tworzona jasnym i zrozumiałym językiem, treść publikacji winna być zgodna z rzeczywistością i tworzona przez wiarygodnych ludzi, co więcej - powinna być medium informacyjnym, gdyż rola opiniotwórcza tytułu - zdaniem re- 
spondentów - należy do dzienników ogólnopolskich (PBC, 2010). Wydaje się zatem, że czytelnik sam potrafi ocenić wydarzenia i zjawiska mające miejsce w środowisku lokalnym, doskonale mu znanym. Inne badania czytelnictwa sprzed siedmiu lat - z 2003 r. (Lokalne Badania Społeczne) udowodniły, iż prasa lokalna w mniejszych aglomeracja miejskich i na wsiach przeważa nad ogólnopolską (Lokalne Badania Społeczne, 2010). Wiele osób nie czyta żadnej innej prasy - poza lokalną. Co więcej, informacja lokalna jest najważniejszym powodem po sięganie do tytułów lokalnych. Odbiorcami są osoby z różnych grup wieku, płci, wykształcenia czy dochodów (Jóżko, 2005).

Z drugiej strony, ciekawe są też oczekiwania samych dziennikarzy od mediów lokalnych. Badania kierowane przez Bogusławę DobekOstrowską pokazały rozdźwięk pomiędzy dziennikarskimi deklaracjami odnośnie standardów zawodowych, a oceną ich realizacji w praktyce (Barczyszyn, 2016, s. 53). A zatem dziennikarze podkreślali rolę etyki zawodowej i standardów, przy jednoczesnej ocenie negatywnej ich realizacji. Ponadto, zjawisko wielozadaniowości w pracy dziennikarskiej skutkuje obniżeniem jakości pracy dziennikarzy (Sobera, 2016, s. 75). Cenną w tym względzie informacją są również prace nadsyłane w różnych konkursach dziennikarstwa lokalnego. Publikacje na konkurs dotyczą zazwyczaj materiałów interwencyjnych i śledczych oraz historycznych kontekstów. Jednak każdorazowo zespół oceniający składający się z dziennikarzy - chciałby, aby redakcje prasy lokalnej w swoich tytułach promowały pomysły na artykuły służące lokalnym społecznościom, wyróżniały próby odejścia od dziennikarskich schematów, popularyzowały wartki język narracyjny i poprawną polszczyznę oraz wyszukiwały ciekawe formy prezentowania osobliwości „małych ojczyzn”, a zwłaszcza pokazywały pozytywny obraz Polski lokalnej (Stowarzyszenie Prasy Lokalnej, 2007). W kontekście powyższych rozważań media lokalne zdaniem oceniających dziennikarzy - powinny być ważnym elementem integrującym społeczność lokalną wokół idei, problemu czy wydarzenia.

Przemiany jakościowe i strukturalne inaczej kształtują się w czasopismach typu samorządowego i prywatnego (komercyjnego), a w każdym przypadku mają za zadanie przyciagnąć czytelnika, zwiększyć atrakcyjność tytułu. W prasie samorządowej najczęściej zmiana dotyczyła przejścia na formę bezpłatnego periodyku oraz zmniejszenie częstotliwości wydawniczej tytułu. Zmiany w prasie i w redakcji dotyczą głównie inicjatyw prywatnych, a obejmują następujące aspekty: wzrasta liczba konkurencyjnych czasopism bezpłatnych o jednorazowym nakładzie po- 
wyżej 15 tys. egz. (media sieciowe - Polskapresse); powstają konsorcja reklamowo-ogłoszeniowe (np. porozumienie P4 w Wielkopolsce od 1998 r.) i w rezultacie do tytułu dołączane są dodatki - np. „Rolnictwo”, „Dom”, „Finanse”, „Zdrowie”, „TeleWizja” itp.; zmianie ulega układ i szata graficzna pisma (strona tytułowa, zmiana czcionki, wprowadzenie zdjęć wielkoformatowych - np. „Panorama Leszczyńska” była nagradzana wielokrotnie - ostatnio w maju 2016 r. - za niebanalne okładki); rozwijanie własnego kolportażu; prenumerata w wersji tradycyjnej i elektronicznej; tworzenie własnych portali i wydań elektronicznych czasopism (w niektórych przypadkach rezygnacja $\mathrm{z}$ druku na rzecz portalu, np. „Słowo Ziemi Wschowskiej”); tworzenie własnych archiwów odpłatnych i nieodpłatnych (najczęściej w formie elektronicznej); zamieszczanie publikacji odpłatnych w wersji elektronicznej prasy lokalnej (np. sport w „Radio Elka”); budowanie własnej marki poprzez wspieranie wydarzeń lokalnych (patronat medialny) oraz organizowanie konkursów i przeprowadzanie regularnych sondaży (aktywizowanie czytelnika). Zarówno w przypadku prasy typu samorządowego, jak i prywatnego treści lokalne uzupełniane są coraz częściej wiadomościami z pierwszych stron gazet ogólnopolskich. Ten ostatni element ma na celu podniesienie atrakcyjności pisma (np. Euro 2012). Poza tym, częste balansowanie pomiędzy misją a komercją, a zatem zamieszczanie w coraz większej ilości treści o charakterze sensacyjnym, stosując formy typowe dla tabloidu ogranicza warsztat dziennikarza, podobnie jak aktywność sieciowa dziennikarzy zatrudnionych tylko do obsługi prasy i portalu w Internecie (brana jest pod uwagę w przypadku zatrudnienia - kreatywność i umiejętności technologiczne kandydata na dziennikarza, a nie doświadczenie w tradycyjnej prasie). Oprócz tego, jak dowiodły badania, w Polsce niezmiennie widoczny jest eskapizm w prasie lokalnej (Michel, 2016, s. 152). Lokalne władze i elity dysponują zarówno instrumentami politycznymi, jak i ekonomicznymi (wykorzystując przy tym tendencje mediów lokalnych do sieciowania czy zjawisko cyfryzacji mediów lokalnych), aby wywierać wpływ na media lokalne. Analiza wynikająca z obserwacji i badań jakościowych - poczyniona, głównie na mediach wielkopolskich, pokazuje, że media lokalne ulegają ciągłym przemianom. Jednakże trend ten widoczny jest nie tylko w polskiej prasie lokalnej, ale też w innych europejskich systemach medialnych, co więcej w skali kraju - analizując stan mediów lokalnych - coraz bardziej widoczna jest konkurencja crossmedialna i tzw. „lokalna komunikacja laicka” (Michalczyk, 2016, s. 29; Oniszczuk, 2016, s. 16-18). 


\section{Bibliografia}

Adamczyk W. (2011), W krzywym zwierciadle: propagandowa funkcja biuletynów samorzadowych, „Przegląd Politologiczny”, nr 1.

Adamowski J. W. (2007), Brytyjskie lokalne i regionalne środki przekazu. Zarys problematyki, w: Regionalne i lokalne środki przekazu. Kontekst międzynarodowy i krajowy, red. J. W. Adamowski, K. Wolny-Zmorzyński, Wydawnictwo ASPRA-JR, Warszawa.

Barczyszyn P. (2016), Standardy dziennikarskie i ich ocena przez dziennikarzy, w: Zmiana $w$ dziennikarstwie w Polsce, Rosji i Szwecji. Analiza porównawcza, red. B. Dobek-Ostrowska, P. Barczyszyn, Wydawnictwo Uniwersytetu Wrocławskiego, Wrocław.

Biernacka-Ligięza I. (2012), Lokalna prasa norweska w dobie globalizacji, Wydawnictwo UMCS, Lublin.

Chorązki W. (1994), Obraz niezależnej prasy lokalnej w Polsce w I pot. 1994 r., Kraków.

Chorązki W. (1999), Media lokalne i sublokalne, „Zeszyty Prasoznawcze”, nr 1-2.

Dobek-Ostrowska B., Barczyszyn P., Michel A. (2013), Zmiana w dziennikarstwie, Kultura zawodowa polskich dziennikarzy, „Studia Medioznawcze”, nr 1.

Dobek-Ostrowska B., Barczyszyn P. (red.), (2016), Zmiana w dziennikarstwie w Polsce, Rosji i Szwecji. Analiza porównawcza, Wydawnictwo Uniwersytetu Wrocławskiego, Wrocław.

Dobek-Ostrowska B. (2011), Polski system medialny na rozdrożu. Media w polityce, polityka w mediach, Wydawnictwo Uniwersytetu Wrocławskiego, Wrocław.

Dziki S., Chorązki W. (2000), Media lokalne i regionalne, w: Dziennikarstwo i świat mediów, red. Z. Bauer, E. Chudziński, Universitas, Kraków.

Filas R. (2010), Dwadzieścia lat przemian polskich mediów (1989-2009) w ujęciu periodycznym, ,Zeszyty Prasoznawcze”, nr 3-4.

Gierula M. (2006), Dziennikarze współczesnej prasy lokalnej, w: Media i komunikowanie $w$ spoleczeństwie demokratycznym. Szkice medioznawcze, red. S. Michalczyk, Wydawnictwo Wyższej Szkoły Zarządzania i Marketingu w Sosnowcu, Sosnowiec.

Gierula M. (2005), Polska prasa lokalna 1989-2000. Typologia i społeczne funkcjonowanie, Wydawnictwo Uniwersytetu Śląskiego, Katowice.

Hayn P. (2012), Internet jako nowa forma komunikowania politycznego, w sytuacji kryzysowej, w: Wspótczesne media. Kryzys w mediach, red. I. Hofman, D. Kępa-Figura, t. 2, Wydawnictwo UMCS, Lublin.

Hofman I., D. Kępa-Figura (red.), (2012), Wspótczesne media. Kryzys w mediach, t. 1-2, Wydawnictwo UMCS, Lublin.

Izba Wydawców Prasy (2014), Prasa lokalna w Polsce 2014, sytuacja, główne problemy, perspektywy rozwoju, http://www.iwp.pl/pliki/Polska_prasa_lokalna_ raport_20140331.pdf, 16.05.2016. 
Jachimowski M. (2006), Regiony periodycznej komunikacji medialnej. Studium prasoznawczo-politologiczne o demokratyzacji komunikacji medialnej, Wydawnictwo Uniwersytetu Śląskiego, Katowice.

Jóźko M. (2005), Prasa lokalna i regionalna jako element społeczeństwa obywatelskiego, w: Media lokalne a demokracja lokalna, red. J. Chłopecki, R. Polak, Rzeszów.

Jurga-Wosik E. (2012), Dwie dekady przeobrażeń mediów lokalnych południowo-zachodniej Wielkopolski, „Środkowoeuropejskie Studia Polityczne”, nr 1.

Jurga-Wosik E. (2015a), Organizacja i przeksztatcenia strukturalno-jakościowe mediów lokalnych leszczyńskiego regionu wydawniczego, w: Przemiany mediów regionalnych i lokalnych, red. W. Furman, P. Kuca, Wydawnictwo Uniwersytetu Rzeszowskiego, Rzeszów.

Jurga-Wosik E. (2015b), Współczesne czasopisma lokalne w Wielkopolsce, w: Przyjaciel Ludu 1834-1849, red. J. M. Halec, Wydawnictwo Cicer, Leszno.

Jurga-Wosik E. (2010), Zarys historii prasy lokalnej poludniowo-zachodniej Wielkopolski, w: Między historia, politologiq a medioznawstwem. Wybór problemów, red. T. Wallas, Wydawnictwo Naukowe WNPiD, Poznań 2010.

Kaczmarczyk M., Szastak-Zięba D. (2009), Zarzqdzanie redakcja prasowa, AWR EDYTOR, Katowice.

Kalińska A. (2016), Media w Polsce. Do kogo należa gazety lokalne i największe czasopisma?, http://www.money.pl/gospodarka/wiadomosci/artykul/mediaw-polsce-do-kogo-naleza-gazety-lokalne,217,2,1996761.html, 30.12.2016.

Kopecka-Piech K. (2011), Koncepcje konwergencji mediów, „Studia Medioznawcze", nr 3 .

Kosiorowski Z. (2010), Regres elektronicznych mediów lokalnych w Polsce, „Zeszyty Prasoznawcze", nr 3-4.

Kowalczyk R. (2008), Media lokalne w Polsce, Wydawnictwo Contact, Poznań.

Kowalczyk R. (2010), Prasa lokalna w Wielkopolsce (1990-2010), w: Media dawne i współczesne, red. B. Kosmanowa, t. V, Poznań.

Kowalczyk R. (2003), Rola prasy lokalnej w kształtowaniu systemu politycznego (wybrane zagadnienia), w: W kręgu mediów i polityki, red. D. Piontek, Wydawnictwo Naukowe INPID UAM, Poznań.

Kowalski T., Jung B. (2006), Media na rynku. Wprowadzenie do ekonomiki mediów, Wydawnictwa Akademickie i Profesjonalne, Warszawa.

Lisowska-Magdziarz M. (2008), Media powszednie. Środki komunikowania masowego i szerokie paradygmaty medialne $w$ życiu codziennym Polaków u progu XXI wieku, Wydawnictwo UJ, Kraków.

Lobka-Pietras A. (2003), My chcemy wiedzieć co się u nas dzieje, w: Media lokalne, w świecie wolności i ograniczeń, red. I. Borkowski, A. Woźny, Oficyna Wydawnicza Arboretum, Wrocław. 
Lokalne Badania (2010), http://www.lokalnebadania.com/wp-content/uploads/2010/02/prasa-lokalna-i-regionalna-jako-element-spoleczenstwa-obywatelskiego, 5.07.2011.

Majewski R. (2004), Procesy integracyjne wydawców wielkopolskich, w: Prasa lokalna $w$ budowie spoleczeństwa obywatelskiego. Materiały z konferencji zorganizowanej przez Komisję Kultury i Środków Przekazu przy wspótudziale Izby Wydawców Prasy pod patronatem Marszałka Senatu RP Longina Pastusiaka 21 września 2004 r., Kancelaria Senatu.

Mała encyklopedia wiedzy politologicznej (2001), red. M. Chmaj, W. Sokół, Wydawnictwo Adam Marszałek, Torun.

Mikułowski Pomorski J. (2008), Zmieniający się świat mediów, Universitas, Kraków.

Michalczyk S. (red.), (2006), Media i komunikowanie w społeczeństwie demokratycznym. Szkice medioznawcze, Wydawnictwo WSZiM w Sosnowcu.

Michalczyk S. (2000), Media lokalne w systemie komunikowania, Wydawnictwo Uniwersytetu Śląskiego, Katowice.

Michalczyk S. (2010), Obszary badawcze w komunikowaniu lokalnym, w: Media lokalne i dziennikarstwo. Aspekty wspótczesne i historyczne, red. K. PokornaIgnatowicz, S. Michalczyk, Krakowska Akademia im. Frycza Modrzewskiego, Kraków.

Michalczyk S. (2016), Praktyczne wymiary dziennikarstwa lokalnego, w: Oblicza mediów lokalnych i regionalnych. Szkice medioznawcze, red. S. Michalczyk, D. Krawczyk, Wydawnictwo Instytut Mikołowski, Mikołów.

Michel A. (2016), Zaangażowanie polityczne dziennikarzy, w: Zmiana w dziennikarstwie w Polsce, Rosji i Szwecji. Analiza porównawcza, Wydawnictwo Uniwersytetu Wrocławskiego, Wrocław.

Murawska-Najmiec E. (2005), Informacja o celach i metodach polityki państwa $w$ zakresie radiofonii i telewizji lokalnej na podstawie wybranych przykładów z krajów europejskich, w: Analiza Biura KRRiT, nr 6.

Oniszczuk Z. (red.), (2016), Strukturalne nastepstwa cyfryzacji w niemieckim systemie medialnym, w: Systemy medialne w dobie cyfryzacji. Kierunki i skala przemian, Wydawnictwo Uniwersytetu Śląskiego, Katowice.

Obrona lokalności i demokracji lokalnej. Strategia działania Krajowej Rady Radiofonii i Telewizji, KRRiT (2008), Warszawa.

Pisarek W. (1978), Prasa - nasz chleb powszedni, Ossolineum, Wrocław.

Pepliński W. (2001), Zmiany w modelu funkcjonowania zawodu dziennikarskiego po 1989 r. (na przykładzie gdańskiego środowiska prasowego), „Studia Medioznawcze", nr 3.

Piasecki A. K. (2003), Samorzq̨d terytorialny a media lokalne (1990-2002). Próba syntezy, „Zeszyty Prasoznawcze”, nr 1-2, Kraków.

Polskie Badania Czytelnictwa (2010), www.pbczyt.p/badanie/items/90.html, 5.07.2011. 
Polak R. (2010), Lokalne portale internetowe jako nowe narzędzie komunikowania lokalnego (na przykładzie województwa podkarpackiego), w: Media lokalne i dziennikarstwo. Aspekty współczesne i historyczne, red. K. Pokorna-Ignatowicz, S. Michalczyk, Krakowska Akademia im. Frycza Modrzewskiego, Kraków.

Polak R. (2005), Prasa lokalna i sublokalna w województwie podkarpackim, w: Media lokalne a demokracja lokalna, red. J. Chłopecki, R. Polak, Rzeszów.

Pokrzycka L. (2009), Prasa ogólnoinformacyjna $w$ regionie lubelskim po 1989 r., Wydawnictwo UMCS, Lublin.

Przybylska A. (2010), Internet i komunikowanie we wspólnocie lokalnej, Wydawnictwo Uniwersytetu Warszawskiego, Warszawa.

Rubaj A. (2016), Konsekwencje cyfryzacji na przykładzie Portugalii, Systemy medialne w dobie cyfryzacji. Kierunki i skala przemian, Wydawnictwo Uniwersytetu Śląskiego, Katowice.

Sobera W. (2016), Problem wielofunkcyjności w zawodzie dziennikarskim, w: Zmiana w dziennikarstwie w Polsce, Rosji i Szwecji. Analiza porównawcza, Wydawnictwo Uniwersytetu Wrocławskiego, Wrocław.

Stępińska A., Jurga-Wosik E., Adamczewska K., Secler B., Narożna D. (2016), Journalistic role performance in Poland, „Środkowoeuropejskie Studia Polityczne", nr 2.

Stępińska A., Ossowski S. (2011a), Społeczne oczekiwania a autostereotyp dziennikarzy polskich $w$ XXI wieku, w: Stereotypy w obszarze społecznym i politycznym, red. B. Pająk-Patkowska, Wydział Nauk Politycznych i Dziennikarstwa UAM, Poznań.

Stępińska A., Ossowski S. (2011b), Dziennikarze w Polsce: wartości, priorytety i standardy zawodowe, „Studia Medioznawcze”, nr 1.

Stępińska A., Ossowski S. (2011c), Kariera, kontrola, stużba społeczna - postawy różnych pokoleń polskich dziennikarzy, w: Studia nad dziennikarstwem, red. I. Hoffman, UMCS, Lublin.

Stowarzyszenie Prasy Lokalnej (2007), http://www.spl.top.pl/konkursy_VIIISPL2007_1.html, 5.05.2011.

Szostok P., Rajczyk R. (2013), Komunikowanie lokalne w Polsce. O instrumentach polityki komunikacyjnej samorzqdów, Wydawnictwo Gnome, Katowice.

Szot L. (2013), Dziennikarze mediów lokalnych w Polsce. Między profesjonalizmem a koniecznościa przetrwania, Wydawnictwo Uniwersytetu Wrocławskiego, Wrocław.

Szynol A. (2007), Dziennikarz lokalny w obliczu interesów politycznych i biznesowych redakcji, w: Media w Polsce. Pierwsza władza IV RP?, red. M. Sokołowski, Wydawnictwa Akademickie i Profesjonalne, Warszawa.

Wojtak M. (2008), Mozaika gatunkowa w tygodniku regionalnym, w: Media regionalne. Sukcesy i porażki, red. J. Adamowski, K. Wolny-Zmorzyński, W. Furman, Wydawnictwo Wyższej Szkoły Ekonomii i Prawa im. prof. Edwarda Lipińskiego w Kielcach, Kielce 2008. 


\section{Structural and qualitative transformations in the local media}

\section{Summary}

Local media deserve attention due to their thematic proximity to the audience. Typically, there are four primary formats of the local media: traditional printed press, local radio, local television and online portals. Local media often prevail quantitatively in different national media systems (for instance: traditional printed press: Poland - 2,000-2,500 titles, Germany - 1,500 titles; digitalized local press: Portugal -170 titles) playing a significant role in the life of respective societies. Empirical studies conducted by Anna Przybylska show that being in regular contact with local media has a positive influence on people's attachment to their place of residence and social commitment of residents. The objective of this paper is to address the problems Polish local media face and the directions of their development. The research hypothesis here is as follows: the transformations of Polish local media pertain to structure and quality. Therefore, both journalistic working styles and the content of the local press are evolving. One of the primary triggers of these changes involves the dynamic advancement of technology. This raises the question about the direction of these transformations and their aftermath, as well as what new quality in local journalism they bring about.

Key words: local media, qualitative transformation, journalism 